\title{
NiETZSCHE Y EL DEVENIR VITAL: DE LO INORGÁNICO A LO ORGÁNICO
}

\author{
Pablo Martínez Becerra ${ }^{1}$
}

\begin{abstract}
Resumen: Nietzsche entiende que el mundo se despliega como voluntad de poder. Si queremos comprender adecuadamente esta perspectiva cosmológica, debemos partir atribuyendo actividad inmanente no solo a los organismos, sino, también, a los seres llamados "inorgánicos". Contando con ello, en este artículo examinamos, de modo "ascendente", los rasgos del devenir vital en ambos estratos, es decir, desde los minerales con sus atracciones y repulsiones hasta llegar al mismo hombre y sus operaciones conscientes. Todos los problemas implicados en esta perspectiva monista son abordados desde argumentaciones que tienen como referente las lecturas de Nietzsche. Strauss, Dubois Reymond, Herzen, Spencer, Lange, Delfœuf, vienen a ser algunas de las fuentes citadas que permiten que este escrito pueda dar cuenta de cómo Nietzsche hace que la vida impere, más allá del ser, como el fenómeno primordial en todos los órdenes.
\end{abstract}

Palabras clave: Nietzsche. Vida. Voluntad de poder. Inorgánico. Orgánico. Conciencia

\section{INTRODUCCIÓN}

Es fundamental en la filosofía de Nietzsche, la idea de que todo tiende al acrecentamiento y que la vida, en general, es lucha. Si esto lo llevamos a otro lenguaje, diremos que su pensar considera que el devenir de la vida es "voluntad de poder" (NIETZSCHE, 1999g, p. 301; 1999e, p. 233).

Afirmar que el mundo de los seres orgánicos se manifiesta como voluntad de poder y lucha, es una consideración que, para los familiarizados con la filosofía de Nietzsche, no entraña mayores dificultades para ser

\footnotetext{
${ }_{1}^{1}$ Profesor de ética de la Universidad de Playa Ancha (UPLA), Valparaíso - Chile. (i) https://orcid. org/0000-0002-2866-6694 E-mail: pablo.martinez@upla.cl

Doctor en filosofía, moral y política por la Universidad de Valencia (Espańa). Coordinador de Investigación de la Facultad de Humanidades en la UPLA. Actualmente investiga en la ética del desarrollo de Martha Nussbaum y, junto a Francisco Cordero, en la teoría de la justicia del filósofo chileno Jenaro Abasolo.
}

http://dx.doi.org/10.1590/0101-3173.2020.v43n4.18.p283 
defendida, puesto que resultan ilustrativas, al respecto, sus descripciones del devenir vital en sus diversas escalas. Así, por ejemplo, Nietzsche hace explícita esta tendencia al crecimiento, mostrando cómo el protoplasma extiende sus "falsos pedúnculos" (Pseudopodien) para "apropiarse e incorporar" lo que se le resiste (NIETZSCHE, 1999f, p. 424), o bien, dando cuenta de la forma en que un individuo como Napoleón lleva a cabo su "colonización espiritual" (geistigen Colonisation) (NIETZSCHE, 2001, p. 121) como fruto de su fuerza expansiva. Sin embargo, fundamentar que en el mundo inorgánico, también llamado el ámbito de la materia bruta o inerte, hay una búsqueda de "un más de vida” (aumento) y que, en este afán, se despliega agonalmente, presenta una serie de dificultades, incluso para los especialistas, puesto que Nietzsche no abunda en el problema y, como veremos, los argumentos y ejemplos son, más bien, ocasionales y están diseminados en sus fragmentos póstumos (Nietzsche, 1999c, p. 499; $)^{2}$.

Esta última consideración, con sus problemas interpretativos, pretendemos que ocupe una parte importante de este escrito, es decir, aspiramos a mostrar la índole aumentativa de lo "inorgánico" y sus implicancias. Por lo que procuraremos, por un lado, hacer visible cómo sustenta Nietzsche la idea de que en este estrato hay también voluntad de poder y lucha y, por otro, caracterizarlo en la medida de lo posible.

Partiremos con esta dificultad, para, luego, ascender al examen de las manifestaciones peculiares que tiene la voluntad de poder en el mundo “orgánico". Tendremos presente cómo se da la expansión vital en las células, en las plantas y, finalmente, en los animales y en el mismo hombre. Dejaremos de lado, en esta ocasión, el modo de vida de los Estados, sociedades, pueblos, etc., es decir, de aquello que Spencer llamaba "superorgánico".

Partamos por la consideración que hace Nietzsche del "mundo inorgánico”.

\section{LA VOLUNTAD DE PODER EN LO INORGÁNICO}

Según un tópico interpretativo, Schopenhauer legaba a Nietzsche la consideración, implícita, de que la voluntad de poder se manifiesta en el mundo humano y, explícitamente, que en lo inorgánico solo habría voluntad

\footnotetext{
2 Podemos nombrar, además, como referencias, Nietzsche, 1999f, p.16; 1999f.p.35s; 1999d, p.406;
} 1999d, p.404; 1999e, p.560; 1999c, p.524, entre otras. 
de persistir y una sujeción "a la ley de gravedad” (SCHOPENHAUER, 2009, p. 439). Pero Nietzsche, como es sabido, termina leyendo todo lo real como voluntad de poder, por lo que debe extrapolar la capacidad de aumento y de lucha también al mundo inorgánico (NIETZSCHE, 1999e, p. 504). Según ha venido estableciendo la hermenéutica de Nietzsche más contextualista ${ }^{3}$, buena parte de sus lecturas "científicas" (Zöllner, Boscovich, Vogt, Spir, Kopp, etc.) posibilitan que él pueda dar cuenta, con mayores argumentos, del dinamismo aumentativo propio de los seres llamados "inertes"4.

\section{1 ACTIVIDAD INORGÁNICA}

Al entender de Nietzsche, lo inorgánico posee una fuerza de atracción y de rechazo que lo liga al mundo orgánico. Por tanto, hablar del mundo inorgánico como el mundo de lo inerte es completamente inadecuado (NIETZSCHE, 1999e, p. 504). Lo inerte, es decir, lo carente de dinamismo, lo que no puede cambiar, es, para Nietzsche, algo que sólo puede pensarse, pero no existir. En este sentido, Nietzsche afirma que "el mundo que es (seiende) es una invención poética; hay solamente un mundo que deviene. ¡De este modo puede ser!” (NIETZSCHE, 1999e, p. 44). Según considera Nietzsche, si llegamos al fondo de lo inorgánico, lo que ahí encontramos no es extensión, ni tampoco un substratum, sino una cantidad de fuerza, un quantum de poder en permanente fluctuación respecto a lo que se le resiste (NIETZSCHE, 1999f, p. 142-143). En otras palabras, la realidad es ella misma acción y lo que llamamos inorgánico viene a manifestar, no la unidad de la "materia", sino ese tema único del mundo, a saber: la voluntad de poder. Ciertamente, no percibimos todas las manifestaciones del movimiento de las fuerzas del mundo inorgánico, pero, no por ello, carece del dinamismo de aquello que sí se manifiesta a nuestra sensibilidad. Dice Nietzsche (1999f, p. 97-98) mostrando nuestra ignorancia sobre los diversos procesos del mundo:

\footnotetext{
3 Esta perspectiva interpretativa que fue inaugurada por Claire Richter (Nietzsche et les théories biologiques contemporaines. Paris: Mercure de France, 1911) y Charles Andler (Nietzsche. Sa vie et sa pensée, 6 v., Paris: Bossard, 1920-1931), se ha desarrollado gracias a C. P. JANZ (1987), SchlechtaAnders (1962), entre otros, y se ha ido completando, rigurosamente, por medio de la revista alemana Nietzsche-Studien. Esta última, ha sido un modelo de línea editorial seguido por otras publicaciones sobre Nietzsche en diversos países. Una figura canónica de esta corriente contextualista es Giuliano Campioni.

${ }^{4}$ Para el tema del despliegue de la voluntad en Schopenhauer, desde lo inorgánico hasta la voluntad de poder manifestada en el hombre, véase CORDERO (2007, p.53-61). El texto incluye un cuadro en que se ilustran gradualmente las diversas formas en que se manifiesta la voluntad en el mundo.
} 
Una cosa=sus propiedades: pero estas son iguales a todo lo que nos concierne en esa cosa: una unidad bajo la cual se pueden resumir las relaciones que para nosotros entran en consideración.

Lo que "entra en consideración" para nosotros de lo inorgánico es su resistencia, no su movimiento.

Ideas semejantes a las expuestas se encuentran con claridad en muchos autores del siglo XIX, entre los cuales se cuenta Spencer que, como sabemos fue repudiado, pero, a su vez, muy aprovechado por Nietzsche ${ }^{5}$. El filósofo inglés afirma que esos "centros de fuerza, atrayéndose y repeliéndose mutuamente en todas direcciones [están] provistos de las propiedades comunes e inseparables de las partes perceptibles" (SPENCER, 1898, p. 234). En otras palabras, esas manifestaciones imperceptibles de la fuerza en lo inorgánico, también podrían ser interpretadas, a partir del lenguaje y la representación, en términos de "volumen", "forma", "calidad", etc., si, efectivamente, guardasen proporción con nuestra sensibilidad.

Como sabemos, Nietzsche desde muy joven intenta equilibrar su formación unilateral, a través de lecturas científicas. Y, específicamente, esa formación que, según él mismo considera, es deficiente, la intenta potenciar, no solo a través de los escritos de Boscovich, Zöllner, Kopp y otros, pedidos cuando era profesor en Basilea ${ }^{6}$, sino con la filosofía de la ciencia presente en la

\footnotetext{
${ }^{5}$ Nietzsche contaba en su biblioteca personal con tres libros de Herbert Spencer en versión alemana, a saber: Die Thatsachen der Ethik, Stuttgart: E. Schweizerbart'sche Verlagshandlung (E. Koch), 1879; Einleitung in das Studium der Sociologie, Leipzig: F. A. Brockhaus, 1875, VI Internationale Wissenschaftliche Bibliothek, XIV. Band, y Einleitung in das Studium der Sociologie, Leipzig: F. A. Brockhaus, 1875, VI, Internationale Wissenschaftliche Bibliothek, XIV. Band (Campioni; D'Iorio; Fornari, Fronterotta; Orsucci A, 2003, p.565-566). En Spencer encontraba Nietzsche una concepción en la que el conocimiento científico se alza desde imágenes que configurar una interpretación de una realidad siempre desconocida, esta idea es semejante a las defendidas por Carpenter, Helmholtz, Tyndall, Lange, junto a otros. Este último, Lange, en su Historia del materialismo ya daba las claves para que Nietzsche, en su apasionada lectura, conociese las ideas, cosmológicas y psicológicas, presentes en los Primeros principios de Spencer. Dice Lange comentando a Spencer: "lo físico solo se presupone y, por lo tanto, puede disolverse en cierto sentido en lo psíquico. De hecho, nuestras representaciones sobre la materia y sus movimientos son solo un tipo de representaciones» ([...] das Physische nur vorausgesetzt wird und sich also in gewissem Sinne in Psychisches auflösen läßt. In der Tat sind unsre Vorstellungen von einer Materie und ihren Bewegungen eben auch nur eine Art von Vorstellungen) (Lange, 1875, p.398).

6 "Despues de la Naturaleza de los cometas de Zöllner fue la Philosophiae naturalis Theoria del jesuita R. J. Boscovich, famoso y discutido en su tiempo, cuya obra Nietzsche sacó por primera vez de la biblioteca de la Universidad de Basilea el 28 de marzo de 1873, obra que vuelve a sacar siempre en cortos intervalos de tiempo y que aprecia mucho. Pero también una Historia de la Química de Kopp,
} 
Historia del materialismo de Lange cuya primera edición lee teniendo 21 ańos. Como señala Janz (1987, p. 227), Nietzsche

[...] siente dolorosamente también la unilateralidad de su formación, de su saber y de su situación intelectual, como insuficiente para un filósofo, y se preocupa ahora realmente de la ampliación, abortada en principio por la temprana cátedra, al ámbito de las ciencias y de la matemática.

Hay que añadir que ya en los fragmentos escritos en los años sesenta - precisamente en su disertación la Teleología a partir de Kant - se ve cómo Nietzsche se prescribe a sí mismo leer a Moleschott, Vogt, Virchow, Bichat, Czolbe y hasta al mismísimo Wundt (NIETZSCHE, 1999h, p. 572). En estas lecturas, encuentra argumentos para ir configurando su idea de la vida como devenir y para asignar a lo inorgánico el carácter de la voluntad de poder. Por ejemplo, una fuente muy estimable de la cual se sirve Nietzsche para sustentar la idea de que lo inorgánico es voluntad de poder y no una expresión inerte de átomos materiales, se encuentra en las consideraciones que hace el jesuita Boscovich sobre las fuerzas repulsivas y atractivas de la naturaleza. Sostiene Nietzsche (1985, p. 33):

En lo que se refiere al atomismo materialista: es una de las cosas mejor refutadas que existen; y acaso no haya ya hoy en Europa entre los doctos nadie tan indocto que continúe atribuyéndole una significación seria, excepto para uso manual y doméstico (es decir, como una abreviación de los medios expresivos) - gracias sobre todo al polaco Boscovich, que, junto con el polaco Copérnico, ha sido hoy el adversario más grande y victorioso de la apariencia visible.

Para el científico ragusiano, los átomos carecen de extensión y, por lo tanto, no pueden rebotar al entrar en contacto unos con otros, sino que poseen fuerzas repulsivas. Sostiene Boscovich (1922, p. 392):

Conferencias sobre el desarrollo de la Química de Ladenburg, una Teoría general del movimiento y la fuerza de Mohr, La maravillosa construcción de universo de Mädler, Elementos de física de Pouillet y Pensamiento y realidad, aparecida justamente entonces, de African Spir: todo ello se lo llevó el mismo día 28 de marzo de la biblioteca y lo trabajó, a pesar de su dolencia de ojos, conciliándolos con sus "lecturas obligatorias"” (JANZ, 1987, p.227-228).

7 Se puede consultar al respecto la traducción, que incluye Introducción, de la Teleología a partir de Kant hecha por Pablo Martínez Becerra y Javier Kasahara Barrientos en la revista Intus-legere, año 2006, n 9, v.2, pp.155-169 e Intus-legere año 2007, nº 1, v.1, pp.121-134. 
No admito la extensión totalmente continua de la materia, sino que constituida por puntos perfectamente indivisibles, inextensos, separados unos de otros por ciertos intervalos y conectados entre sí por ciertas fuerzas que son ya atractivas, ya repulsivas, dependientes de su distancia mutua" ${ }^{8}$.

Ciertamente, Nietzsche, siguiendo a Faraday, preferiría hablar, sin negar a Boscovich, de "simples centros de fuerza" (CRAWFORD, 1988, p. 88). De hecho, a las cosas las conocemos por sus manifestaciones, por su acción, en primer término, sobre nuestros sentidos. Por tanto, la materia, como fondo, como ese susbtratum del mundo, aparece, por un lado, como una ficción nacida de una "necesidad psíquica" y, por otra, como una parcela de no-devenir, como algo inerte, que insertamos en la realidad. Al decir de Nietzsche: "Todos los supuestos previos del mecanismo, materia, átomo, presión y choque, gravedad, no son "hechos en sî", sino interpretaciones con ayuda de ficciones psíquicas" (NIETZSCHE, 1999g, p. 262). Para ilustrar esto, se puede decir que si algo puede ser palpable no es por su materia, como ya establecimos, sino por su fuerza de resistencia. Nietzsche diría que se trata de una fuerza que ansía más fuerza, es decir, de voluntad poder: "la vida como la forma de ser que mejor conocemos es, específicamente, una voluntad de acumulación de fuerza [...] es esencialmente un esfuerzo a más poder" (NIETZSCHE, 1999g, p. 262)

Nietzsche, además, en la Fisiología de la voluntad de Alexander Herzen, hijo, (1839-1906), había encontrado una oposición clara a este dualismo que divide al mundo físico de tal manera que lo hace ver como si estuviese constituido por un substratum material inerte que sólo puede ser móvil por medio de una fuerza que se le sobreañade?. Para Herzen $(1874$, p. 2), esta opinión está ya rebatida y resulta ser "totalmente artificial". Al entender del hijo adoptivo de Malwida von Meysenburg, "los atributos que nosotros llamamos materia son puntos de fuerza” (HERZEN, 1874, p. 2). Se advierte, entonces, que la crítica del sustrato, se le aparecía a Nietzsche por diversos flancos - entre los que podemos nombrar, junto a Herzen, a Taine, a Ribot y

\footnotetext{
${ }^{8}$ Ego materiae extensionem prorsus continuam non admitto, sed eam constituo punctis prorsus indivisibilibus, $\&$ inextensis a se invicem disjunctis aliquo intervallo, \& connexis per vires quasdam jam attractivas, jam repulsivas pendentes a mutuis ipsorum distantiis.

9 Ernst Pfeiffer señala, documentadamente, que la obra de Herzen (hijo), "Nietzsche y Rée la habían leído juntos en Sorrento" (NIETZSCHE; SALOMÉ; RÉE, p.261). Además, Nietzsche tenía es su biblioteca personal el libro de Herzen titulado Le Cerveau et l'activité cérébrale. Paris: J. B. Baillière et fils, 1887.
} 
a los diversos colaboradores de la Revue philosophique - y no solo a través de Boscovich (CAMPIONI, 2001).

Ahora bien, para ser justos, las concepciones que Nietzsche extrae de la mayor parte de estos filósofos de la ciencia que consulta y estudia, habían pasado por la criba interpretativa de Lange. Es decir, si Nietzsche puede moverse a ratos con soltura en estas visiones científicas es, en primer término, por la capacidad de síntesis y crítica del profesor de Manburgo. Es más, ni siquiera aquellos autores que, por múltiples razones, no aparecen en la Historia del materialismo, pueden librarse ser leídos por Nietzsche desde el inamovible sello langeano. Al respecto de esta impronta expresa Salaquarda (1978, p. 253):

Nietzsche, a pesar de todos los cambios y nuevos enfoques, permaneció orientado hacia Lange en puntos importantes de su pensamiento y en su comprensión de la filosofía en general. Además, ha tomado una gran cantidad de pensamientos, motivos y sugerencias individuales de la Historia del materialismo, a través de los cuales su evaluación de las tendencias contemporáneas ha sido coloreada o incluso determinada en términos positivos y negativos.

Se puede sostener ahora con los elementos ya expuestos, que el factum del movimiento y de la fuerza, es un factum que no puede encontrar explicación desde la conservación, sino desde el aumento que le es inherente. Dicho de otro modo, la actividad es aquello que justamente se extiende hacia el poder. Se puede agregar que la fuerza, en cuanto tiene duración no pude manifestarse más que en la oposición, es decir, en la lucha.

\section{2 "VIDA" INORGÁNICA}

Es necesario abordar, ahora, un punto bastante complejo. Nietzsche después de sostener el carácter dinámico del mundo, se atreve a afirmar lo siguiente: "la voluntad de poder gobierna el mundo inorgánico, o mejor dicho, no existe ningún mundo inorgánico" (NIETZSCHE, 1999e, p. 504). Dicho de otra manera, si, a su entender, la voluntad de poder es devenir, y el devenir es equivalente a la vida, se concluye que lo inorgánico es, también, vida. Si tomamos todo el peso de la afirmación, es lícito que nos preguntemos si acaso el tópico del Nietzsche "vitalista" es tan cierto como suele afirmarse. ¿No es acaso Nietzsche, según esto, un filósofo hylozoista y monista? 
Aunque parezca extraño, Nietzsche, en el libro de Strauss titulado Antigua y nueva fe, que él mismo había vilipendiado hasta el paroxismo, encuentra el cuestionamiento respecto de los verdaderos límites entre lo inorgánico y lo orgánico (CAMPIONI; D’IORIO; FORNARI, 2003, p. 580). Decía Strauss, citando al respetado a Dubois Reymond, que en la ciencia actual: "la distinción entre las llamadas naturaleza inorgánica y orgánica, es bastante arbitraria, y que la fuerza vital, como se suele concebir, es un absurdo" (die Scheidung zwischen der sogenannten organischen und unorganischen Natur ist eine ganz willkürliche; die Lebenskraft, wie sie gewöhnlich gedacht wird, ist ein Unding) (STRAUSS, 1872, p. 171). En el caso de Nietzsche, no habría, según parece, un principio vital irreductible a lo inorgánico, sino un dinamismo general.

Sin embargo, esto no significa de ninguna manera que, a partir de aquí, Nietzsche afirme la generación espontánea o aequivoca. Su opinión es coincidente con lo que se expresa en una de sus lecturas tardías, me refiero al libro La materia bruta y la materia viva. Estudio sobre el origen de la vida y la muerte de Joseph Delfouf (CAMPIONI; D’IORIO; FORNARI, 2003, p. 178). En él, el profesor de Lieja sostiene: "para nosotros no hay pues diferencia esencial entre lo orgánico y lo inorgánico. Puede transformarse uno en otro, aunque por sí mismo lo inorgánico no puede reproducir lo orgánico” (DELBCEUF, 1889, p. 86). Por su parte, Nietzsche sostiene en concordancia: "lo orgánico no es algo originado" (NIETZSCHE, 1999e, p. 117).

Ahora bien, debemos responder la pregunta previa: ¿Nietzsche es o no es hylozoísta? Para ello, tendremos que adelantar, en parte, la caracterización de lo orgánico. Con el fin de contestar, creemos necesario distinguir que en Nietzsche hay dos modos de entender la "vida". El primer modo es, simplemente, como dinamismo y devenir, el segundo modo, es la vida entendida como interpretación, memoria y conocimiento. Ambas diversificaciones, son voluntad de poder y vida, pero solo los seres orgánicos, en cuanto unidades interpretantes, crean un mundo intermedio entre ellos y el devenir, un mundo que llega a alterar su propia identidad. A propósito de esto, Nietzsche agrega: "todo lo orgánico se distingue de lo inorgánico ‘porques va acumulando experiencias, y en ningún momento es idéntico a sí mismo en sus procesos" (NIETZSCHE, 1999d, p. 406). Es decir, el bylozoismo de la voluntad de poder, incorpora un cierto vitalismo a la hora de entrar a distinguir y considerar los matices que tiene el despliegue del aumento en lo orgánico. 


\section{3 "PerCepCIÓN" INORGÁNICA}

Hemos dado un paso en la caracterización de lo inorgánico, pero, este avance, supone que debemos enfrentarnos con otro problema espinoso, como es la atribución de "percepción" a lo inorgánico que Nietzsche realiza. El autor del Zarathustra, parece decir, junto a Giordano Bruno, que "todo vive [...] hasta la piedra siente a su modo por más que el hombre no pueda definir esta manera de sentir" (JANET \& SÉAILLES, 1921, p. 50).

Respecto de este asunto, Müller-Lauter sostiene que esta atribución nace de la premisa nietzscheana que afirma que "ninguna voluntad de poder es "voluntad ciega”" (MÜLLER-LAUTER, 1980, p. 263). En efecto, Nietzsche lo dice expresamente, "esa voluntad de poder, para que pueda manifestarse, tiene que percibir las cosas que atrae hacia sí, que siente la aproximación de algo que es asimilable para ella" (NIETZSCHE, 1999e, p. 503).

Nietzsche, cuando pide el 06 de noviembre de 1872 (SCHLECHTA; ANDERS, 1962, p. 161), el libro La naturaleza de los cometas, ya tenía noticia, gracias a Lange, que Zöllner, profesor de la Universidad de Leipzig, defendía la idea, para muchos absurda, de la percepción en lo inorgánico. Justamente, durante ese periodo Nietzsche escribe lo siguiente, usando todavía un lenguaje propio del atomismo y sin haber establecido aún los contornos claros de la doctrina de la voluntad de poder: "El choque, la acción de un átomo sobre otro, presupone también sensación [Empfindung]. Una cosa extrańa no puede influir en otra" (NIETZSCHE, 1999a, p. 469). Y, añade, que el surgimiento de la conciencia es complejo, pero, el de la sensación no. No obstante, a partir de aquí, la pregunta que surge es qué se percibe a nivel de la mal llamada "materia bruta". Frente a esto, se puede sostener que lo que se percibe es la afinidad y, a su vez, tanto la "diferencia de fuerza" como la aproximación. Es decir, si las fuerzas se encuentran relacionadas, este hecho supone, al entender de Nietzsche, percepción. Un mundo que es concebido por Nietzsche deviniendo desde atracciones, repulsiones y "acción a distancia" y no por un choque directo de masas, parece requerir de un cierto sentirse atraído, de una relación en la que lo otro no es completamente extraño (NIETZSCHE, 1999e, p. 504). Para Nietzsche, la vinculación de las fuerzas no es sólo una relación, sino, también, un "óptica de percepción" (Wahrnehmungs-Optik). Sucede que si Nietzsche considera que la voluntad de poder se despliega, indefectiblemente, de modo perspectivístico, esto solo es posible "si todo ser fuese, esencialmente, algo que percibe” (NIETZSCHE, 1999f, p. 188). 


\section{4 DISTINCIÓN ENTRE PERCEPCIÓN ORGÁNICA E INORGÁNICA}

Hay en Nietzsche, en ciertos periodos y en pasajes bien precisos, consideraciones que proponen la superioridad del mundo inorgánico (NIETZSCHE, 1999f, p. 36; Martínez, 2007, p. 252-265). Esta superioridad va de la mano, por un lado, de estimar que la vida constituye un "accidente", una "excepción", algo accesorio dentro del caos y la lucha de quanta de fuerzas (NIETZSCHE, 2001, p. 202) y, por otro, de dar valor a la ausencia de refinamiento en la confrontación perspectivista respecto del mundo exterior. En otras palabras, Nietzsche no estima que lo inorgánico carece de perspectiva, puesto que la esencia del mundo es desplegarse de modo perspectivo, sino que esa óptica, que es privilegio de lo inorgánico, es completamente "definida" (NIETZSCHE, 1999e, p. 537). Dicho de otro modo, las percepciones del mundo inorgánico son seguras y se mantienen alejadas del error y en este sentido, dice Nietzsche, su perspectiva no tiene la "limitación" derivada de la vacilación que añade la "vida" (NIETZSCHE, 1999f, p. 36). Para Nietzsche, ya al nivel protoplasmático empieza la inseguridad y la inestabilidad, debido a que se introduce un prisma valorativo que se centra en fortalecer las propias condiciones de existencia desde la complejización interior. Nietzsche dice: "el tránsito del mundo de lo inorgánico al mundo de lo orgánico es un tránsito de percepciones definidas de los valores de fuerza y relaciones de poder a percepciones inseguras, indefinidas (porque una multitud de entes trabados en lucha entre sí [= protoplasma] se sienten confrontados con el mundo exterior)" (NIETZSCHE, 1999e, p. 537). Se podría afirmar, de acuerdo con esto, que los seres inorgánicos son uniperspectivos y los orgánicos multiperspectivos en el sentido de que los primeros carecen de la tensión interna que confiere la "fantasía" y las diversas tendencias instintivas y, tan solo, se restringen a una síntesis de fuerzas.

Nietzsche (1999e, p. 537) insiste en esta concepción, expresando que

[...] en el mundo químico reina la más agudísima percepción de la diferencia de fuerza. Un protoplasma, en cambio, en cuanto multiplicidad de fuerzas quimicas, se caracteriza por una percepción global insegura e indefinida de una cosa extrańa.

En razón de esto, llega a defender la superioridad de lo inorgánico, es decir, a causa de que en lo inorgánico la fijación de fuerza es cabal y precisa. Afirma Nietzsche al respecto: "el mundo inorgánico que está detrás es la máxima síntesis de fuerza y, por lo tanto, lo supremo y más venerable. ¡Ahí 
falta el error, la limitación de perspectiva!" (NIETZSCHE, 1999f, p. 36). Es decir, como argumentamos más arriba, la perspectiva alcanzada no está "limitada" por el refinamiento del conato interno que suponen las imágenes y las pulsiones.

Nietzsche (1999e, p. 536) sostiene en un fragmento que el mundo inorgánico viene a ser el "reino de la verdad", donde "señorea la verdad". Müller-Lauter, interpretando estas líneas, escribe: "creo que a través de estos y otros apuntes se puede apreciar una nostalgia no disimulada de Nietzsche por esa "verdad", por la verdad, cuya destrucción constituye todavía uno de los fines principales de su filosofía" (MÜLLER-LAUTER, 1980, p. 264). Sin embargo, consideramos, pese a la autoridad de Müller-Lauter, que en estos fragmentos más que nostalgia por la verdad con mayúscula, se trata de un anhelo de un desenvolvimiento vital, seguro, fácil, sin dilatación que viene a ser un modelo para el mismo despliegue vital del hombre. En otras palabras, nuestra salida interpretativa, va por el lado de recordar que, para Nietzsche, el hombre ha de poner como fin de su devenir vital, una superanimalidad que debe desarrollarse a partir de instintos más saludables y elevados. Esto permitiría, que el hombre, por supuesto sólo en cierto grado, no se mirase en los diversos espejos de su conciencia, antes de ejercer su actividad vital. En otras palabras, lo que a Nietzsche le interesa, es que el hombre logre desplegarse desde el automatismo hermenéutico del instinto (NIETZSCHE; 1999 g, p. 326). Con esto, el ser humano puede manifestarse, siguiendo una imagen de Emerson, como un verdadero acontecimiento de la naturaleza. Es decir, como lo haría un volcán, un río o un movimiento telúrico. Justamente, cuando Nietzsche habla del "automatismo instintivo", como el modo más libre de llevar a cabo la vida humana, se refiere a la facilidad en el actuar que se vuelve imposible cuando se ha superfetado y exagerado el rol de la conciencia. Por eso, estimamos que la apreciación de lo inorgánico no se liga con un ideal de la vida teórica (la búsqueda de la "Verdad"), sino con un ideal práctico de un movimiento vital, semejante al inorgánico, sin dilatación, aporía, desgarro y remordimiento.

Todo lo expresado, no quiere decir que lo inorgánico no posea una suerte de "interior". Es más, para Nietzsche, lo verdaderamente exterior es la sensibilidad, el placer el dolor, el conocimiento, etc. Estas manifestaciones, pueden considerarse como modos depurados de acrecentar el poder y una especialización en su búsqueda, pero, también, como "la parte externa de la existencia, como un error del ser, una aventura” (NIETZSCHE, 1999c, p. 
468). Basta con recordar que la voluntad de poder es un "acontecer interior" (innerlichen Geschehens), un pathos - idea que viene a ahondar, según lo entiende el mismo Nietzsche, la concepción dinámica de la fuerza-, que se metamorfosea en distintos síntomas. Sin embargo, en lo inorgánico, para expresarlo de algún modo, la voluntad de poder parece no manifestar síntomas (errores), sino el aumento en "bruto". Jaspers (2003, p. 325), en un evidente esfuerzo explicativo, sostiene que la voluntad de poder en lo inorgánico se expresa "por completo idéntica a sí misma: indivisa, siempre actual y manifiesta".

Después de estas aclaraciones respecto a lo inorgánico, veamos a continuación el modo de manifestarse el devenir de la vida en lo "orgánico".

\section{LA VOLUNTAD DE PODER EN LO ORGÁNICO}

En general, tomando en cuenta los matices señalados, se puede afirmar que lo orgánico es "multiperspectivo", o sea, configura en torno a sí mundos fantaseados. Estos mundos, nos dice Nietzsche, son el reino del error, pero de un error que es condición de su aumento. Como hemos indicado, Nietzsche, en cierta etapa, tiende a evaluar la complejidad propia de lo orgánico como inferior a la simplicidad de lo inorgánico. Lo orgánico supone una división, una exterioridad, que se aleja del carácter sintético de lo inorgánico (NIETZSCHE, 1999f, p. 36; 1999c, p. 468). Sin embargo, es manifiesto que Nietzsche, finalmente, termina considerando a lo orgánico como superior y como una configuración más refinada del poder. Concordando con ello, Rüdiger Grimm describe la evidente especialización de lo orgánico, en oposición a lo inorgánico, explicando que "aquello que distingue a la vida de lo que llamamos materia inorgánica inerte es su mayor complejidad, su mayor diversidad y su mayor capacidad para dominar, asimilar y controlar otros quanta de poder" (GRIMM, 1977, p. 7).

Sin embargo, la división entre mundo inorgánico y orgánico, para Nietzsche, ha de ser vista sólo de modo parcial puesto que en uno y otro mundo aparece el pathos de la voluntad de poder, expresado en el "impulso de aproximación y el impulso de rechazar” (NIETZSCHE, 1999e, p. 560).

Nietzsche estima que los gruesos errores en la comprensión de la "vida” en general y, con ello, de la psiquis humana, descansan en la desviación metódica que desliga estas indagaciones de la observación de los distintos 
fenómenos de la naturaleza. Es decir, el primer error surge cuando aquello que se dice - esa suerte de fórmula comprensiva del mundo -, vale tan sólo para el hombre. En contraste con esta perspectiva sesgada, Nietzsche (1999g, p. 52) sostiene que "para comprender qué es la vida, qué especie de esfuerzo y tensión (Streben und Spannung) sea la vida, la fórmula debe valer tanto para el árbol y la planta como para el animal”. En razón de ello, cuando Nietzsche se pregunta “¿a qué tiende la planta?", va a responder con una concepción que sirve para entender la globalidad de la vida: todo lo vivo tiende a expandirse, a crecer, a ser más.

\subsection{La CÉlULA}

Los seres orgánicos, en sus diversos niveles, incluida la célula, se elevan a una actividad psíquica. La célula, por lo mismo que desenvuelve su vitalidad desde la memoria, desarrolla, al entender de Nietzsche, un movimiento psicofisiológico de simplificación y de "abreviación del pasado" que está orientado al fomento de la vida (NIETZSCHE, 1999f, p. 139; MARTÍNEZ, 2008, p. 331-341).

Nietzsche afirma que el protoplasma recurre a su estructura para ganar poder y, además, necesita, como todo ser vivo, buscar algo que se le resista para que este poder se manifieste. El mismo proceso de nutrición se presenta, a su vez, como "una aplicación de aquella voluntad primordial de devenir más fuerte” (NIETZSCHE, 1999g, p. 360). En consonancia con esta opinión, Nietzsche afirma que "también el yo-espiritual está dado ya en la célula" (NIETZSCHE, 1999e, p. 157). Teniendo en cuenta estos juicios, podemos asegurar que debe haber sido totalmente del gusto de Nietzsche, leer en los Diálogos filosóficos de Renan (1876, p. 90) que "la célula es ya una pequeña concentración personal".

Hay que agregar que ni siquiera los microorganismos, como sostiene Binet en patente coincidencia con Nietzsche, presentan una irritabilidad a secas, puesto que toda ella se presenta como una actividad inteligente. En otras palabras, se puede sostener que a partir del ser orgánico empieza una labor artística que, simplificando el caos, crea apariencias desde los estímulos y excitaciones (NIETZSCHE, 1999e, p. 97).

Para Nietzsche, la índole exclusiva del ser humano no descansa en su inserción en el "orden moral". Esto se debe a que lo orgánico, desde la célula, 
define su mundo circundante, sus simplificaciones, desde criterios de "simpatía" y "antipatía" que Nietzsche inscribe dentro de este ámbito. Se simplifica para la vida y, en ese sentido, esa operación de abreviación y logificación es "práctica" (moral). Dice expresamente Nietzsche (1999c, p. 274): "Hasta dentro de la célula, no hay otros movimientos que no sean "morales" en este sentido". Ciertamente, en el mundo humano la moral aparece con la singularidad de que esas aversiones e inclinaciones primordiales, se transfiguran al nivel de las "costumbres", adquieren conciencia de sí e incluso se elevan a la reflexión de la filosofía práctica. Sin embargo, en este ethos que se defiende, con frecuencia a partir de sistemas filosóficos, sigue hablando el pathos primordial inconsciente. Por ello, en este sentido, Nietzsche (1999e, p. 219) llega a sostener: "considero todas las morales habidas como edificadas sobre hipótesis acerca de los medios para asegurar la conservación de un tipo". Sin duda, Nietzsche se refiere aquí a "tipos" humanos, pero, esta argumentación vale para todos los modos de vida orgánica. Es decir, la moral puede entenderse como la defensa, con una gran carga atávica, de un modus vivendi presente en todos los niveles orgánicos. La moral es el modo de vida acreditado, es decir, la defensa de lo acostumbrado. En Nietzsche, toda forma de vivir implica ya evaluar, estimar en un sentido práctico y desde "prejuicios", que no pueden menos que llamarse movimientos "morales". Para todo ser vivo, allí donde están las actividades que expanden su vida, en ese mismo sitio, está también su "deber".

Ciertamente, Nietzsche afirma que es nuestra racionalidad la que transpone el despliegue vital del "ser animado más bajo" a su propio lenguaje, $y$, en esta medida, no se ve otra cosa que "impulsos morales". Por ejemplo, si observamos que un pequeño organismo "procura asimilar lo más posible, no tan sólo compensar la pérdida”, diremos, desde nuestras categorías morales, que "es codicioso" (NIETZSCHE, 1999c, 490). Además, cuando observamos sus movimientos al momento de enfrentar a un rival que se muestra como fuerza opositora, expresaremos que ese organismo no sólo "lucha", sino que "odia, teme, disimula" (NIETZSCHE, 1999c, p. 491). No obstante, desde Nietzsche, la moral que podríamos llamar - de modo visiblemente redundante si nos situamos desde un prisma tradicional_, "humana", bien puede considerarse como un ámbito que, también, a causa de nuestro propio análisis racional, se concibe, por un lado, como totalmente desligado de nuestras antipatías y simpatías fisiológicas y, por otro, como una esfera aparte de "la vida que quiere en nosotros" ya desde la dimensión inconsciente. Es decir, la razón humana le da un carácter moral a cierto despliegue de la vida en el hombre, olvidando que en rigor esta vida sólo tiene un significado físico. En otras palabras, cuando 
las voluntades de poder se manifiestan en las relaciones entre los hombres, a este enfrentamiento de fuerzas, lo llamamos "moral". Parece ser que nuestra racionalidad, ya en el momento en que se refiere al hombre mismo, debe reconocer en su análisis, ámbitos que, perteneciendo, según Nietzsche, a una manifestación y diversificación más de la voluntad de poder, se conciben con un en sí y, además, integrando una dimensión irreductible.

\section{2. LAS PLANTAS}

Nietzsche, conforme a su concepción de la vida de las plantas, bien podría hacerse cargo de las siguientes palabras de Maeterlinck: "Todas [las "plantas y flores torpes o desgraciadas"] se aplican al cumplimiento de su obra; todas tienen la magnifica ambición de invadir y conquistar la superficie del globo multiplicando hasta el infinito la forma de existencia que representan" (MAETERLINCK, 1914, p. 7). Es más, las plantas saben apoyarse, como de un andamiaje estructural, de aquellos seres que les permite orientarse a su propio crecimiento. Nietzsche pone el ejemplo del "sipó matador" que logra elevarse por sobre aquellos vegetales que le han servido de rodrigón natural (NIETZSCHE, 1985, p. 221). Ya Goethe había sostenido que las plantas se metamorfosean desde "una egoística tenacidad genérica y específica” (GOETHE, s/d, p. 464). Esta idea, sin dificultad, nos recuerda este modo sintético en que la voluntad de poder se manifiesta en el mundo orgánico, según la concepción nietzscheana. Los organismos, desde los unicelulares hasta los más complejos, constituyen una suerte de ego que, sin ser manifestación de una sustancia, aunque sí de su lucha interna, aspiran a la afirmación y expansión de su modo vivir.

Añadamos que Nietzsche cuando se refiere al "mundo vegetal", evidencia la huella de Goethe, que no tarda en oponer a Darwin $^{10}$, pero, además, la de Emerson que "leía y comentaba [...]

10 "La teoría de la evolución de Charles Darwin confronta a Nietzsche con la Metamorfosis de las plantas de Goethe de 1790 [...] A partir de la metamorfosis de las plantas, Nietzsche se hará la gran pregunta: “¿dónde ha crecido hasta ahora la planta "hombre" de forma más espléndida?» (BENNE, 2004, p.338). 
continuamente, y su influencia se puede rastrear a lo largo de sus obras publicadas e inéditas, desde sus primeros escritos filosóficos Fatum und Geschichte y Über Willensfreiheit und Fatum (1862) hasta su última obra publicada, el Crepúsculo de los idolos (1888)" (ZAVATTA, p. 511). Con Goethe, por un lado, viene a reafirmar, junto a lo más arriba mencionado, la idea que entiende al organismo vegetal, y a todo lo vivo, como un conjunto de individuos. El propio Nietzsche citando la Metamorfosis de las plantas ${ }^{11}$ en la Teleologia a partir de Kant, escribe: "Todo viviente, dice Goethe, no es un singular, sino una multiplicidad: también cuando aparece como individuo, permanece siempre una reunión de seres vivientes autónomos" (Nietzsche, 1999h, p. 556; Martínez, 2007, p. 149) Basta con recordar que Goethe (1997, p. 123) expresa en su Teoría de la naturaleza "[...] que una planta no es una unidad, sino que es una criatura compuesta de muchas unidades [...]”. Como refuerza Salaquarda: "Nietzsche habrá mencionado que Lange, en este contexto, cita una tesis de Goethe, según la cual todos los seres vivos aparecen como "individuos", pero en realidad "representan un conjunto de seres vivos independientes" " (SALAQUARDA, 1978, p. 247). De Emerson, por otro lado, a la par de extraer una visión de la naturaleza y su despliegue, va a sacar útiles metáforas que permiten caracterizar la vitalidad humana, comparándola con la planta. Por ejemplo, la concepción de las plantas como seres que interpretan desde dentro hacia fuera se extrapola a los seres humanos: "El hombre - dice Emerson - es aquella noble planta endógena que crece, como la palmera, de dentro afuera" (EMERSON, 1943, p. 9). Incluso, Nietzsche se compara a sí mismo, al filósofo y a ciertos delincuentes con una "planta rara". Es curioso ver que en el temprano escrito titulado De mi vida, junto con describir la flora de su pueblo y suelo natal, señala que nació "como planta" en las tierras de Röcken (NIETZSCHE, 1996, p. 220).

\footnotetext{
${ }^{11}$ En rigor la frase se encuentra en el escrito que precede a la Metamorfosis titulado Bildung und Umbildung organischer Naturen.
} 
En última instancia, uno de los criterios utilizados por Nietzsche para establecer las jerarquías morfológicas de la voluntad de poder, va a ser el aumento de la capacidad de simulación. Nietzsche (1999f, p. 550) sostiene, explícitamente: "El crecimiento de la "simulación" conforma la jerarquía ascendente de los seres. En el mundo inorgánico, ella parece faltar, en lo orgánico comienza la astucia: las plantas son maestras en ello". Está afirmando que el actuar con astucia, significa ya incorporar perspectivas desde diversas valoraciones. En todo ser vivo hay un despliegue práctico del conocimiento, es decir, un desenvolvimiento vital que tiende a asegurar aquellas condiciones de existencia que le permiten aumentar. Cada ser vivo estima y valora para acondicionar su mundo, esto lleva a Nietzsche (1999a, p. 469) a exclamar: "Para las plantas el mundo es planta, para nosotros hombre".

\section{3 ANimal y hombre}

Como es manifiesto, dentro de esta especie de "monismo-naturalista" de Nietzsche, es posible ascender en los grados de "vida".

La vida del animal, de modo no muy distinto a las plantas, tiene en el instinto su motor y dirección. Estos diversos instintos no presentan en él mayores contradicciones entre sí, por este motivo, la actividad del animal se presenta diáfana, sin aporías y, debido a ello, saludable. Pese a haber en él, como en todo ser orgánico, un cierto tenerse presente, su expansión vital no se realiza a partir del rol centralizador que la conciencia tiene en el hombre. Por lo mismo, el animal vive de un modo no-histórico y sin rumiar el pasado.

En hombres y animales, la actividad psíquica en sus múltiples niveles se deriva de los instintos y mantiene su conexión con ellos. Sin embargo, sólo la "planta-hombre" eleva su actividad instintiva en un proceso que quizá sea su distinción, es decir, en lo que Nietzsche denomina "transfiguración" y "sublimación" (Nietzsche, 1999c, p. 486). Es evidente que, escribe Martínez (2007, p. 152),

[...] para Nietzsche, los instintos decadentes, por ejemplo, del ámbito sexual podrían desenvolverse transformados en "filantropía, adoración de María y de los santos, fantasía artística” (Nietzsche, 1999c, p. 486). 
El mismo filosofar platónico surge de un "instinto sexual sublimado (sublimirter)" (Nietzsche, 1999c, p. 486)".

Ciertamente, de acuerdo con el filósofo, toda actividad cognoscitiva y afectiva tiene en los seres vivos la posibilidad de ser llamada "espiritual" y, por lo mismo, le cabe ser considerada como una elevación o sublimación de lo puramente físico. Sin embargo, la sublimación humana tiende a radicalizar la brecha con los grados más bajos hasta llegar, en buena medida, a escindir la actividad conciente, cultural, civilizada, artística, literaria, filosófica, etc., de su origen y base instintiva.

Es decir, lo que se ha elevado desde los instintos tiende a desgarrarse de los mismos. El hombre parece sentir los peldaños previos de transfiguración no como grados progresivos y dependientes, sino como antítesis (Gegensätze) (NIETZSCHE, 1999c, p. 482). En el fondo, el ser humano mediante sus productos conscientes, lo que hace con la vida es intentar corregirla a costa de oponerse a los instintos.

Los impulsos en el hombre se contradicen de manera constante y no siempre el cuerpo alcanza autorregulación a partir de ellos. La condición del animal es distinta en este aspecto, ya que "en él todos los instintos existentes cumplen tareas perfectamente determinadas" (NIETZSCHE, 1999e, p. 182). Sin duda, Nietzsche, al afirmar esto no está defendiendo la fijeza de los instintos animales y desconociendo que ellos también "obran, según piensa Espinas $^{12}$, en virtud de móviles individuales, susceptibles de modificarse a tenor de las circunstancias" (BÜCHNER, s/d, p. 26). Por ello, concordando con el filósofo francés, a Nietzsche le podría parecer más acertado afirmar, además, que "[...] el instinto no es de ningún modo una constante específica, sino una variable dependiente de dos fuerzas: la influencias hereditarias y las influencias del medio" (ESPINAS, 1877, p. 281). Mas, pese a esta visión que da más plasticidad al desenvolvimiento instintivo, el animal parece reestructurar sus instintos sin pasar a un plano reflexivo comparable al de la conciencia humana. Debido a esto, como señalamos, el animal o resuelve las dificultades que su circunstancia le pone por delante desde los instintos, o sucumbe. No existe para el animal esa alternativa que sí genera la evolución

${ }^{12}$ La obra de Espinas más conocida, Des sociétés animales, había sido editada en francés un año después de la Büchner (1877), y en alemán en 1879. Nietzsche, por su parte, tenía en su biblioteca personal esta traducción alemana y aparece con múltiples anotaciones (CAMPIONI; D’IORIO; FORNARI, 2003, p.218-219). 
humana, como es la de mirarse a sí mismo a una altura reflexiva que, unida al desarrollo de la "capacidad comunicativa" y lingüística, se vuelca hacia su interior y, a la vez, sobre la comunidad (NIETZSCHE, 2001, p. 350). Sin duda, en el hombre se refina la actividad impulsiva y el despliegue de la vida cuando se genera la "conciencia". Sin embargo, el surgimiento de la conciencia, guarda relación con la incapacidad de sintetizar las contradicciones de los impulsos (NIETZSCHE, 2001, p. 351). Al entender de Nietzsche, gracias al surgimiento de la conciencia el hombre evita desaparecer, pero, con ella incorporada, su vida no se desenvuelve ya, nunca más, teniendo como centro la facilidad propia que supone la hermenéutica del instinto (NIETZSCHE, 2001, p. 352).

El hombre para obrar adecuadamente debe consultar, constantemente, tanto a sí mismo a partir de su conciencia del yo, como a la comunidad que habita en él bajo la forma de conciencia moral. De este modo, el ser humano se transforma en el único animal que, teniendo la capacidad de autorreflexión racional, la enfermedad parece serle algo connatural. En efecto, la conciencia le permite al hombre ser un animal que "inventa" la risa, el juego y la actividad que se considera que vale por sí misma, mas, a la vez, amplifica su sufrimiento y refina su crueldad (NIETZSCHE, 1999e, p. 576; 1999b, p. 432).

Sin dejar de afirmar lo establecido, cabe hacer algunas salvedades. Es patente que podemos deslindar rasgos comunes e imperantes en los hombres que le diferencian del animal, entre los que se cuenta la enfermedad implicada en la superfetación de la conciencia. Con todo, para Nietzsche, estas determinaciones pueden variar en ciertas épocas y, con más evidencia, en ciertos individuos. Es decir, de tiempo en tiempo, manifestándose la salud en el despliegue humano, se generan momentos estelares (Renacimiento) y personalidades descollantes (Napoleón) en la historia (CAMPIONI, 2001, p. 156-165).

El criterio para juzgar esas expresiones vitales como superiores es, precisamente, el imperio de una vida instintiva saludable. Para ilustrar este asunto, es útil fijarnos que la admiración de Nietzsche por Napoleón (CAMPIONI, 2001, p. 156-165), para muchos odiosa, descansa en su autorregulación orgánica interna en la que la conciencia ejerce una función secundaria. Esta admiración no es muy distinta a la que profesó Goethe por el general francés, es decir, se relaciona con el carácter natural y daimónico que éste poseía. En él no hay desdoble interno entre lo que se es y lo que se debería ser. Napoleón viene a ser, para Goethe, una pura actividad de la naturaleza 
y, en razón de esto y sin guardarse encomios, le llama "ese compendio del mundo" (ECKERMANN, 1949, p. 141). En Napoleón la vida humana, que Goethe se esfuerza por restituirla en su conexión a la naturaleza - incluso buscando el hueso intermaxilar en el hombre-, aparece sintetizando la vida en general. En este mismo sentido se expresa Emerson, cuando juzga que "Bonaparte ańadía a esa fuerza mineral y animal el discernimiento y la generalización de tal modo que los hombres veían combinados en él el poder natural y la potencia intelectual, como si el mar y la tierra se hubiesen hecho carne y comenzado a calcular (as if the sea and land had taken flash and begun to cipher)" (EMERSON, 1943, p. 148). Napoleón, calculando, generalizando, planificando, continúa siendo "un experimento, en las condiciones más favorables, de los poderes del intelecto sin conciencia (the powers of intellect without conscience)" (EMERSON, 1943, p. 165). Como expresa Taine (1887, p. 12), en Napoleón el instinto se hace centro de toda su actividad, haciendo posible su "yo colosal" y su egoísmo invasor.

La vida humana, tanto para su economía como para su florecimiento, requiere del automatismo instintivo. El instinto surge de un proceso de habituación que adeuda su configuración a experiencias de generaciones pasadas. El instinto manifiesta el poder de síntesis de la memoria en los seres orgánicos y la orientación práctica de su actividad. Es claro para Nietzsche, que la conciencia en el hombre es ya un verdadero órgano, pero, no por ello, es de la opinión que los instintos han de cederle su lugar. Así como han de desaparecer algunos instintos, se deben crear las condiciones para el surgimiento de otros nuevos. Por ello, alabar el desenvolvimiento instintivo en el hombre, no es alabar de modo exclusivo la vida impulsiva al nivel de los animales, sino que es valorizar las posibilidades, en extremos amplias, que no daría una conducta desde ellos. Para Nietzsche, nuevos instintos, sanos ciertamente, son nuevas posibilidades para el hombre en la acción inmediata y, a la vez, para la elevación de los mismos en cultura. De la autorregulación interna de los instintos, proviene el carácter y del carácter toda creación, espiritualización y sublimación valiosa.

Nietzsche, seguramente, estaría de acuerdo con la opinión de Taine ${ }^{13}$, para algunos tan colmada de naturalismo como de ingenuidad, que sostiene

${ }^{13}$ Hay diversa formas de documentar la filiación y el aprecio de Nietzsche por Taine. Tengamos presente aquí a Campioni (2001) y la carta de Nietzsche a Rohde del 11 de noviembre de 1887 en que escribe: "Nota bene. Sobre el seńor Taine te ruego recobres el sentido. Esas cosas groseras que dices y piensas de él me irritan. Cosas así se las concedo al príncipe Napoleón; no a mi amigo Rohde. Quien entiende a esta especie de espíritus estrictos y generosos (- T<aine> es hoy el educador de todos los 
que "se puede considerar al hombre como un animal de especie superior, que produce filosofías y poemas más o menos como los gusanos de seda hacen sus capullos, y como las abejas hacen sus colmenas" (TAINE, 1946, p. 7). Es más, Nietzsche (1998, p. 33) se expresa, de forma muy semejante, cuando muestra cómo nos acondicionamos el mundo a través del conocimiento y del lenguaje:

En la construcción de los conceptos trabaja originalmente el lenguaje; más tarde la ciencia. Y así como la abeja construye las celdas y simultáneamente las rellena de miel, así también la ciencia trabaja sin cesar en ese gran columbarium de los conceptos, necrópolis de las intuiciones; construye sin cesar nuevas y más elevadas plantas, apuntala, limpia y renueva las celdas viejas y, sobre todo, se esfuerza en llenar ese colosal andamiaje que desmesuradamente ha apilado y en ordenar dentro de él todo el mundo empírico, es decir, el mundo antropomórfico. Si ya el hombre que actúa ata su vida a la razón y sus conceptos para no ser arrastrado ni perderse a sí mismo, el investigador construye su cabańa junto a la torre de la ciencia para poder cooperar en su edificación y para encontrar él mismo protección bajo ese baluarte ya existente"

Como Taine, Nietzsche estima que en la actividad del hombre y del animal hay especialización y elevación de los instintos. A su vez, el hombre puede reflejar, en esas expresiones vitales - que Taine considera devenidas como rasgos exclusivos de él -, dispersión, degeneración, falta de disciplina interna de los instintos, etc., o bien lo contrario, es decir, salud instintiva. En otras palabras, tanto Nietzsche como Taine, consideran que desde instintos enfermos, se pueden generar una gama de filosofías, poemas y cultura que, como capullos defectuosos, no son frutos de una verdadera "individualidad orgánica”, ya que tan sólo expresan una "individualidad psicológica” que se presenta anémica, deslavada, ausente de carácter y desconectada de la vida. Por eso, según el filósofo alemán, y para dar un ejemplo, jamás se podrá hacer buena música si se es un histérico, un histrión, un enfermo, en vez de un hombre de carácter (NIETZSCHE, 2002).

En último término, el hombre, como la planta, florece desde raíces que se hunden en los recodos más secretos de la tierra. Como afirma el autor de Zarathustra, mientras más penetran esas raíces al fondo de los instintos - a Dionisos para decirlo en metáfora nietzscheana - a más luz y altura pueden elevarse.

caracteres científicos más serios de Francia), de ese no creo sencillamente que comprenda algo de mi propia tarea" (NIETZSCHE, 2012, p.69-70). 


\section{ConClusión}

Guyau (1887, p. 433), con su agudeza y simplicidad característica, sostiene que "[...] vida es una noción acaso más humana, más subjetiva; pero, después de todo, más completa y concreta que las de movimiento y de fuerza”. Nietzsche piensa de la misma manera y, justamente, es esto lo que hemos intentado defender en estas líneas. Es decir, para Nietzsche, en el aparente abismo que media entre aquello que llamamos orgánico y inorgánico, resulta vicaría la "actividad" que responde bien al nombre de "vida".

Según Nietzsche, la vida como voluntad de poder atraviesa desde el mundo de la "materia bruta" hasta el de la "materia viva", pero lo hace de un modo tan dinámico que estos modos de referirse a uno y otro mundo acaban por ser insuficientes en su filosofar. La dinamicidad presente en el modo de obrar de lo inorgánico, tienta a Nietzsche a atribuirle la forma más elemental de vida psíquica y un crecimiento que no se reduce a la yuxtaposición. Respecto a lo primero, tengamos en cuenta que el "modo de vida inorgánico", resiste analogías con el mismo pensar: "“pensar", en el estadio primitivo (preorgánico) - nos dice Nietzsche - es realizar formas, como en los cristales” (NIETZSCHE, 1999e, 687-688). Para aclarar lo segundo, cabría decir que si la voluntad de poder actúa "desde dentro", desde cierta interioridad, parece apropiado afirmar que también lo inorgánico crece por "intususcepción”. En otras palabras, la vida en ningún estrato de su desenvolvimiento es algo que viene a residir en el mundo posteriormente y desde fuera. Al decir de Bouillier (1873, p. 65, "[...] la vida, como debería ser concebida [...] no es el anfitrión que entra en la casa cuando ya está lista, sino el arquitecto que la construye”.

En conformidad con lo anterior, toda manifestación de la naturaleza parece ser un refinamiento del movimiento. Entre las diversas formas de refinamiento, se cuentan, por ejemplo, el "pensamiento", la "voluntad" y la "sensibilidad". Por ello, a Nietzsche, no le resultaría ocioso el cuestionamiento de Cabanis en torno a si acaso está tan justificado diferenciar la "sensibilidad del movimiento". El pensador francés sostiene que "no debemos dejar de notar que esta distinción podría bien desaparecer en un análisis más severo; y que así la sensibilidad se enlaza quizá en algunos puntos esenciales con las causas y las leyes del movimiento, origen general y fecundo de todos los fenómenos del universo" (CABANIS, s/d, p. 114). Sin duda, Nietzsche, no acogería estas últimas consideraciones de Cabanis respecto a las causas y las leyes, pero, sí estimaría que éste considere a todo movimiento, a toda fuerza, no como algo ciego, sino como un modo de "inteligencia" y "sensibilidad". A causa de 
esto, se puede afirmar que la vida psíquica o mental propia de lo orgánico, constituye un aumento en la complejidad del mismo movimiento. Es más, podría establecerse que esas manifestaciones psíquicas están contenidas, de alguna manera y de modo rudimentario, en todo movimiento. En palabras de Nietzsche, si la voluntad de poder puede devenir inteligencia, voluntad, sensibilidad, etc., es porque en su desenvolvimiento más básico, estas expresiones están ya presentes en cierto grado y modo.

Finalmente, podemos sostener que, para Nietzsche, la voluntad de poder permite interpretar la realidad desde la pura inmanencia y, por ello, teniendo un sentido en sí misma. La vida como devenir, el único mundo que existe, reemplaza la comprensión de la realidad a partir del "ser" y sobrepuja más allá del dualismo que le es inherente. Nietzsche, con su idea de vida, dinamiza la realidad, la vuelve fluxión, y la ve en una metamorfosis constante en extrañas formas que responde a nombres, tan humanos demasiado humanos, como "planta", "animal" y "hombre".

BECERRA, P. M. Nietzsche and the vital becoming: from the inorganic to the organic. Trans/ form/ação, Marília, v. 43, n. 4, p. 283-308, Out./Dez., 2020.

\begin{abstract}
Nietzsche understands that the world unfolds as a will to power. If we want to properly understand this cosmological perspective, we must start by attributing immanent activity not only to organisms, but also to beings called "inorganic". With this in mind, in this article we examine, in an "ascending" way, the features of the vital becoming in both strata, that is, from the minerals, with their attractions and repulsions, until reaching the man himself and his conscious operations. All the problems involved in this monistic perspective are approached from argumentations that are based on Nietzsche's readings. Strauss, Dubois Reymond, Herzen, Spencer, Lange, Delfœuf, are some of the cited sources that allow this writing to give an account of how Nietzsche makes life prevail, beyond being, as the primordial phenomenon in all orders.
\end{abstract}

Keywords: Nietzsche. Life. Will to power. Inorganic. Organic. Consciousness

\title{
REFERENCIAS
}

BENNE C. Kanon und Autonomie in Nietzsches Aufklärung. In: Reschke R. (ed.), Nietzsche. Radikalaufklärer oder radikaler Gegenaufklärer?. Berlin: Akademie Verlag. 2004. p. 335-341 
BOSCOVICH, R. A theory of natural philosophy. Latin-English edition from the text of the first Venetian edition published under the personal superintendence of the author in 1763, with a short life of Boscovich. Chicago-London: Open Court Publishing Company, 1922.

BOUILLIER, F. Le principe vital et l'âme pensante. Paris: Didier, 1873.

BÜCHNER, L. La vida psíquica de las bestias. Traducción de José Prat. Valencia: Sempere, s/d.

CABANIS, P. -J. Choix de textes et Introduction par Georges Poyer. Paris: LouisMichaud, s/d.

CAMPIONI, G. Les lectures françaises de Nietzsche. Traduit par Christel LavigneMouilleron. Paris: PUF, 2001.

CAMPIONI, G.; D'IORIO, P; FORNARI, M.C; FRONTEROTTA, F; ORSUCCI A. Nietzsches persönliche Bibliothek. Berlin-New York: Walter de Gruyter, 2003.

CORDERO, F. La creación díscola del mundo o la voluntad como fundamento metafísico en Schopenhauer. Ediciones Universitarias de Valparaíso, Valparaíso, 2007.

CRAWFORD, C. The Beginning of Nietzsche's Theory of Language. Berlin/New York: Walter de Gruyter, 1988.

DELBCEUF, J. La materia bruta y la materia viva. Estudio sobre el origen de la vida y de la muerte. v. 2. Traducción de Antonio Zozaya. Madrid: Librería de R. Angulo, 1889.

ECKERMANN, J. Conversaciones con Goethe. Traducción de Francisco Ayala. Buenos Aires: Jackson, 1949.

EMERSON, R. W. Hombres representativos. Traducción Luis Echávarri. Buenos Aires: Losada, 1943.

ESPINAS, A. Des sociétés animales. Étude de psychologie comparée. Paris: Germer Baillière, 1877.

GOETHE, J. W. Teoría de la naturaleza. Traducción de Diego Sánchez. Madrid: Tecnos, 1997.

GOETHE, J. W. Werke in sechs Bänden. v. 6, Leipzig: Insel, s/d.

GRIMM, R, Nietzsche's theory of knowledge. Berlin: Walter de Gruyter, 1977.

GUYAU, J.-M. L'irreligion de l'avenir: étude sociologique. Paris: Felix Alcan, 1887.

HERZEN, A. Physiologie de la volonté. Traduit par Charles Letourneau. Paris: Germen Baillière, 1874.

JANET, P; SÉAILLES, G. Historie de la philosophie. Les problèmes et les écoles. Paris: Librairie de Lagrave, 1921. 
JANZ, C. P. Friedrich Nietzsche 2. Los diez años de Basilea (1869/1879). Traducción de Jacobo Muñoz e Isidoro Reguera. Madrid: Alianza Editorial, 1987.

JASPERS, K. Nietzsche. Introducción a la comprensión de su filosofar. Traducción de Emilio Estiú. Buenos Aires: Sudamericana, 2003.

\section{LANGE, F. A. Geschichte des Materialismus und Kritikseiner Bedeutung in der}

Gegenwart. v.2. Iserlohn: J. Baedeker, 1875.

MAETERLINCK, M. La inteligencia de las flores. Traducción de Juan Bautista Enseñat. Barcelona: Montaner y Simón, 1914.

MARTÍNEZ, P. Nietzsche y el despliegue de la libertad. Santiago de Chile: RIL, 2007.

MARTÍNEZ, P. Nietzsche y la hermenéutica orgánica. Veritas. Valparaíso, v.19, p. 331342, 2008.

MÜLLER-LAUTER, W. Nietzsche Lehre vom Willen zur Macht. In: SALAQUARDA, J. (Hrsg.). Nietzsche. Darmstadt: Wiss. Buchgesellschaft, 1980. p. 234-287.

NIETZSCHE, F. Correspondencia. Octubre 1887- Enero 1889. Traducción de Joan B. Llinares. Madrid: Trotta, 2012.

NIETZSCHE, F. De mi vida. Traducción de Luis Moreno. Madrid: Valdemar, 1996.

NIETZSCHE, F. El caso Wagner. Nietzsche contra Wagner. Traducción de José Luis Arántegui. Madrid: Siruela, 2002.

NIETZSCHE, F. La ciencia jovial. (La gaya scienza). Traducción de Germán Cano. Madrid: Biblioteca Nueva, 2001.

NIETZSCHE, F. Nachgelassene Aufzeichnungen Herbst 1864-Frühjahr 1868. In: NIETZSCHE, F. Nietzsche Werke. Kritische Gesamtausgabe, v.1/4. Ed. J.Figl- I.Rath, Berlin/New York: Walter de Gruyter, 1999h.

NIETZSCHE, F. Más allá del bien y del mal. Traducción de Andrés Sánchez. Madrid: Alianza Editorial, 1985.

NIETZSCHE, F. Nachlaß 1869-1874. In: NIETZSCHE, F. Sämtliche Werke. Kritische Studienausgabe. v.7. Ed. G. Colli- M. Montinari, Berlin/New York/München: Walter de Gruyter, 1999a.

NIETZSCHE, F. Nachlaß 1875-1879. In: NIETZSCHE, F. Sämtliche Werke. Kritische Studienausgabe. v.8. Ed. G. Colli- M. Montinari, Berlin/New York/München: Walter de Gruyter, 1999b.

NIETZSCHE, F. Nachlaß 1880-1882. In: NIETZSCHE, F. Sämtliche Werke. Kritische Studienausgabe. v.9. Ed. G. Colli- M. Montinari, Berlin/New York/München: Walter de Gruyter, 1999c. 
NIETZSCHE, F. Nachlaß 1882-1884. In: NIETZSCHE, F. Sämtliche Werke. Kritische Studienausgabe. v.10. Ed. G. Colli- M. Montinari, Berlin/New York/München: Walter de Gruyter, 1999d.

NIETZSCHE, F. Nachlaß 1884-1885. In: NIETZSCHE, F. Sämtliche Werke. Kritische Studienausgabe. v.11. Ed. G. Colli- M. Montinari, Berlin/New York/München: Walter de Gruyter, 1999e.

NIETZSCHE, F. Nachlaß 1885-1887. In: NIETZSCHE, F. Sämtliche Werke. Kritische Studienausgabe. v.12. Ed. G. Colli- M. Montinari, Berlin/New York/München: Walter de Gruyter, $1999 f$.

NIETZSCHE, F. Nachlaß 1887-1889. In: NIETZSCHE, F. Sämtliche Werke. Kritische Studienausgabe. v.13. Ed. G. Colli- M. Montinari, Berlin/New York/München: Walter de Gruyter, 1999g.

NIETZSCHE, F. Sobre verdad y mentira en sentido extramoral. Traducción de L. M. Valdés y Teresa Orduña. Madrid: Tecnos, 1998.

NIETZSCHE, F; SALOMÉ, L.; RÉE, P. Documentos de un encuentro. Selección, prólogo y notas por Ernst Pfeiffer. Traducción de Ana María Domenech. Barcelona: Laertes, 1982.

RENAN, E. Dialogues et fragments philosophiques. Paris: Calmann Lévy, 1876.

SALAQUARDA, J. Nietzsche und Lange. Nietzsche-Studien, v.7, p. 236-253. 1978.

SCHLECHTA, K; ANDERS, A. Friedrich Nietzsche. Von den verborgenen Anfängen seines Philosophierens. Stuttgart: Friedrich Frommann, 1962.

SCHOPENHAUER, A. Parerga y paralipómena. v.2. Traducción de Pilar López de Santa María. Madrid: Trotta, 2009.

SPENCER, H. First principles. New York: D. Appleton and Company, 1898.

STRAUSS, D. F. Der alte und der neue Glaube: Ein Bekenntniss. Leipzig: S. Hirzel, 1872.

TAINE, H. La Fontaine y sus fábulas. Traducción de J. M. de Sosa. Buenos Aires: Americalee, 1946.

TAINE, H. Napoleon Bonaparte. Revue des Deux Mondes. Paris, v. LXXX, p. 5-48, 1887.

ZAVATTA, B. Nietzsche and Emerson on friendship and its ethical-political implications. In: Siemens, H; Roodt V. (eds.). Nietzsche, Power and Politics. Rethinking Nietzsche's Legacy for Political Thought. Berlin: De Gruyter. 2008. p. 511-542.

Recebido: 06/3/2018

Aceito: 27/12/2019 